\title{
RNAi AND mIRNA PATHWAYS IN NEMATODES
}

Keywords: dsRNA, siRNA, miRNA, Dicer, Argonaute

\author{
PETR SVOBODA \\ Institute of Molecular Genetics, Academy of Sciences of the Czech Republic, \\ Videnska 1083, 14220 Prague 4, Czech Republic \\ Correspondence to: Petr Svoboda, Institute of Molecular Genetics ASCR, \\ Videnska 1083, 14220 Prague 4, Czech Republic, tel. \#+420 241063147, \\ e-mail: svobodap@img.cas.cz.
}

\begin{abstract}
RNA silencing denotes sequence-specific repression mediated by small RNAs. In metazoa, there are two mechanistically closely related pathways: RNA interference (RNAi) and microRNA (miRNA) pathway. The miRNA pathway regulates endogenous protein-coding gene expression and has been implicated in many biological processes. RNAi generally serves as a form of innate immunity targeting viruses and mobile elements. This review is summarizing information about RNAi and miRNA pathways in the phylum Nematoda. Research on miRNA and RNAi pathways in the phylum Nematoda has been primarily using Caenorhabditis elegans model system and related species. In fact, miRNA and RNAi pathways were both discovered in this model system. Studies in Caenorhabditis elegans revealed highly complex organization of small RNA pathways despite there is just a single Dicer gene. The complexity of small RNA pathways in Caenorhabditis elegans stems from a large number of Argonaute proteins and three RNA-dependent RNA polymerases, which establish an intricate system of primary and secondary small RNAs with different biological functions in the cytoplasm and nucleus. This review focuses on the miRNA pathway and pathways initiated by long dsRNA. The first part introduces the key molecular players of RNA silencing in nematodes. The second summarizes miRNA and dsRNA-induced mechanisms, in this case RNAi (exogenous $=$ exo-RNAi and endogenous $=$ endo-RNAi) and adenosine deamination (nematodes do not have the interferon system like vertebrate groups).
\end{abstract}

\section{Introduction}

Nematodes are free living or parasitic unsegmented pseudocoelomate worms. There is $\sim 80000$ described species, estimates of the total number of species are reaching 1 million (Margulis and Schwartz, 1998). Parasitic nematodes cause disease in animals and plants, thus are of high medical and economical significance. In addition, a free-living soil nematode Caenorhabditis elegans (C. elegans) became a laboratory workhorse for the last half a century that contributed to our understanding of every major molecular mechanism in multicellular organisms. In fact, miRNA and RNAi pathways were both first discovered in C. elegans. 

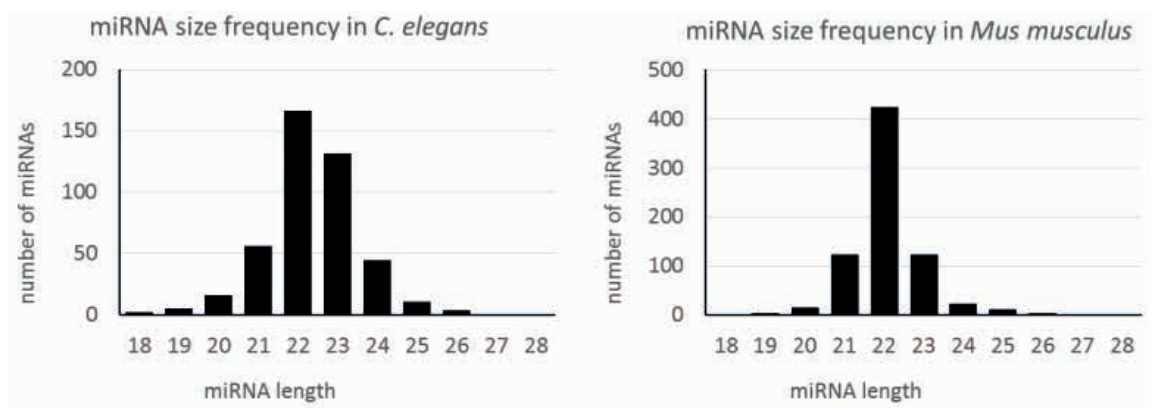

Figure 1 Nematode miRNA lengths

The left graph depicts size distribution of all 334 miRNAs of a C. elegans deposited in the miRBase (version 21). For comparison, the right graph shows size distribution of 721 high-confidence murine miRNAs.

RNA silencing in C. elegans is very complex despite it has only one Dicer gene. The complexity is created by the extreme diversity of downstream pathways, which employ miRNAs as well as primary and secondary siRNA and other small RNAs that are loaded on 26 Argonaute proteins of three subfamilies, which have different biological functions in the cytoplasm and nucleus. For the purpose of the report, I focus on the miRNA pathway and pathways initiated by long dsRNA. This part of the report is organized similarly to the other taxon-oriented reports - first I introduce the key molecular players of RNA silencing in nematodes and then I summarize miRNA and dsRNA-induced mechanisms, in this case RNAi (exogenous $=$ exo-RNAi and endogenous $=$ endo-RNAi) and adenosine deamination (nematodes do not have the interferon system like vertebrate groups).

\section{The Microprocessor complex}

C. elegans utilizes the same Microprocessor complex as the earlier discussed Metazoa, i.e. a complex of Drosha (drsh-1) and DGCR8 homologs, the latter being named Pasha (partner of Drosha, pash-1) (Denli et al., 2004). The complex cleaves the pri-miRNA into pre-miRNA in the nucleus. Suppression of Pasha expression in C. elegans interferes with pri-miRNA processing, leading to an accumulation of pri-miRNAs and a reduction in mature miRNAs (Denli et al., 2004). Furthermore, pash-1 mutation relieves let-7-mediated repression and the phenotype overlaps with those observed in $d c r-1$ or $d r s h-1$ mutants (Denli et al., 2004). NGS of small RNAs showed that Drosha cleavage sites were enriched with specific nucleotides (mainly uridine) and structural distortions resulting in reduced stability on the 5' arm (Warf et al., 2011).

\section{Dicer}

C. elegans genome contains a single Dicer gene (dcr-1), which was discovered as a miRNA and RNAi biogenesis factor in 2001 (Grishok et al., 2001; Ketting et al., 2001; Knight 
and Bass, 2001). Dicer is the central component in biogenesis miRNAs, endo-siRNAs and exo-siRNA. The loss of Dicer results in sterility, abnormal oocytes, and heterochronic phenotypes (Grishok et al., 2001; Ketting et al., 2001; Knight and Bass, 2001).

Most nematodes possessed only one Dicer gene (Gao et al., 2014). Dicer cleaves long dsRNA into $23 \mathrm{bp}$ siRNAs in vitro in the presence of ATP (Ketting et al., 2001). However the length of the primary cleave product is retained only in miRNAs, where C. elegans miRNAs deposited in the miRBase are 22-23 nt long (Fig. 1) and in RDE-1-bound siRNAs in the exo-RNAi. The endogenous siRNAs are longer and belong to the class of 26G RNAs whose biogenesis requires additional factors beyond Dicer.

There is neither crystal structure of C. elegans Dicer nor a cryo-EM analysis of the shape of the molecule. However, the general domain composition of C. elegans Dicer is very similar to that of human Dicer (Fig. 2). Thus, some information can be inferred from sequence comparison as well as from biochemical analyses of isolated domains.

Analysis of the PAZ domain showed that the 5' and 3' pockets are conserved across members of the Dicer1 subfamily, with the exception of the 5' pocket in nematode Bursaphelenchus xylophilus. The helicase domain of Dicer is not necessary for miRNA processing, or exo-RNAi. Comparisons of wild-type and helicase-defective strains showed that the helicase domain is required by a subset of annotated endo-siRNAs, in particular, 26G RNAs (Welker et al., 2010). Consistently with these observations, the helicase domain is essential for cleaving dsRNA with blunt or 5'-overhangs but not with 3' overhangs, such as miRNA precursors (Welker et al., 2011). Further, blunt termini, but not 3' overhangs yield siRNAs from internal regions of dsRNA (Welker et al., 2011). RNAse IIIb and dsRNA binding domains contain two conserved phosphorylation sites, which are phosphorylated by ERK. The phosphorylation is necessary and sufficient to trigger Dicer's nuclear translocation (Drake et al., 2014) and plays a role during oocyte-to-embryo transition (Drake et al., 2014).

C. elegans evolved a system where Dicer processes substrates for different pathways (endogenous RNAi, exogenous RNAi, antiviral defense) into 22 nt small RNAs. Thus, needs to DCR-1 function as a hub for several small RNA pathways where it contributes to sorting of small RNAs into different pathways. This contrasts with mammals, where there is minimal, if any, sorting during loading of Dicer-produced small RNAs, and with Drosophila, which employs two dedicated Dicer proteins for RNAi and miRNA pathways. Sorting involves substrate structure and distinct protein factors (Jannot et al., 2008). Pre-miRNAs have unique structures that facilitate loading onto ALG-1/2 Argonaute proteins. Pre-miRNA analysis showed structural distortions adjacent to Dicer cleavage sites (Warf et al., 2011) and common internal bulges/mismatches. Remarkably, nucleotide changes in the pre-let-7 miRNA precursor that create a perfectly complementary stem cause loading of resulting small RNAs on RDE-1, which is the Argonaute protein acting in the exogenous RNAi pathway (Steiner et al., 2007). Reintroducing mismatches into the stem restores loading onto ALG-1 (Steiner et al., 2007). The second sorting system relies of proteins recognizing Dicer substrates and presenting it to Dicer, such as RDE-4 discussed in the next section, or Dicer associated proteins, which modify DCR-1 products and direct them on distinct Argonaute proteins (see further below).

DCR-1 also binds RNAs without generating small RNAs. Analysis of Dicer-associated RNAs in C. elegans by PAR-CLIP (Photoactivatable Ribonucleoside-Enhanced 


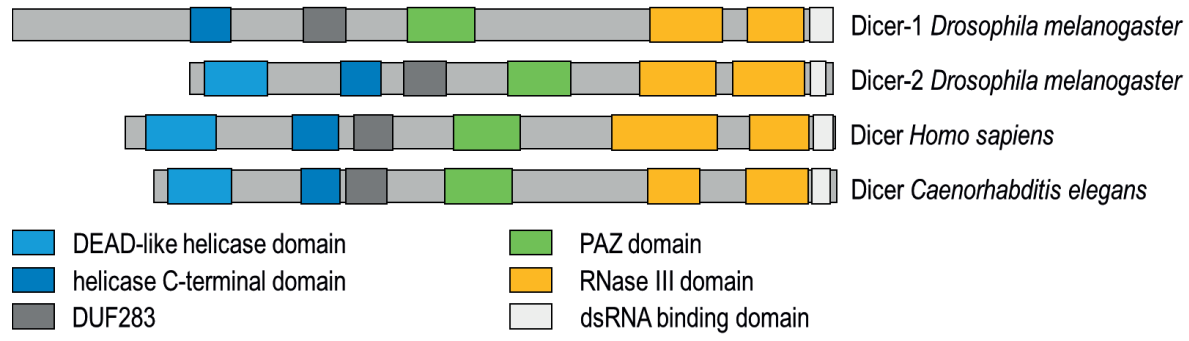

Figure 2 Comparison of $C$. elegans, human and Drosophila Dicer proteins Domain composition was adopted from (Jaskiewicz and Filipowicz, 2008).

Crosslinking and Immunoprecipitation) revealed 2500 Dicer binding sites in the $C$. elegans transcriptome (Rybak-Wolf et al., 2014). Apart from miRNA precursors, DCR-1 also binds a variety of RNA molecules (structural RNAs, promoter RNAs, and mitochondrial transcript). However, Dicer-binding sites beyond miRNAs mostly reside on mRNAs/ lncRNAs that are not significantly processed into small RNAs. These passive binding (i.e. without dicing) typically involves small, Dicer-bound hairpins within intact transcripts and generally stabilizes target expression (Rybak-Wolf et al., 2014). It was proposed that passive binding might be one of the mechanisms balancing siRNA/miRNA production since it was shown that passive binding sites can sequester Dicer and reduce microRNA expression (Rybak-Wolf et al., 2014). For example, a noncoding RNA rncs-1 is a non-cleaved Dicer substrate, which appears to reduce Dicer activity in hypodermis and intestine (Hellwig and Bass, 2008)

Remarkably, two distinct truncated Dicer isoforms produced by proteolytic cleavage were reported from C. elegans. While both isoforms are C-terminal fragments created by proteolytic cleavage, they show profound functional differences. The first one is created by cleavage of DCR-1 by CED-3 caspase. The released $43 \mathrm{kDa}$ C-terminal fragment changes its RNase activity into DNase, which fragments chromosomal DNA during apoptosis (Nakagawa et al., 2010). Subsequent molecular analysis proposed a model where the N-terminal helicase domain is suppressing DNase activity and release of the C-terminal part upon cleavage at Asp1472 (within the RNAse IIIa domain) by CED-3 activates a DNA-binding activity and enables DNA cleavage (Ge et al., 2014). The second truncated form of Dicer exists as a $\sim 95 \mathrm{kDa} C$-terminal Dicer fragment generated by proteolytic cleavage upstream of RNase IIIa domain. It is abundant in adult $C$. elegans cells where it might enhance exogenous and antiviral RNAi while negatively regulating miRNA biogenesis (Sawh and Duchaine, 2013). The $95 \mathrm{kDa}$ Dicer fragment does not interact with RDE-4 nor with the ERI complex but it was found to bind miRNA-associated AGO proteins ALG-1/2 suggesting that it sequesters ALG-1/2 from the full-length DCR-1, thereby acting as a competitive inhibitor of miRNA processing (Sawh and Duchaine, 2013).

There has been a number of identified Dicer binding partners, which form different complexes, which act in different types of RNAi pathways (Duchaine et al., 2006; Lee et al., 2006). One of them is the exo-RNAi Dicer complex composed of RDE-4 (dsRBP), DCR-1, RDE-1 (Argonaute protein), and DRH-1/2 (Dicer-related helicases) (Tabara et al., 
2002). Another complex is ERI/Dicer complex, which was reported for endo-RNAi during sperm development (Pavelec et al., 2009). It is composed of ERI-1/3/5, DCR-1, and RRF-3 (RdRP) and produces 26G primary endo-siRNAs, which then drive production of secondary 22G RNAs (Duchaine et al., 2006; Gent et al., 2009; Han et al., 2009). ERI-1 is an exoribonuclease that degrades siRNAs in vitro (Kennedy et al., 2004) and acts in 26G biogenesis in vivo (Duchaine et al., 2006; Gent et al., 2009; Han et al., 2009), ERI-3 has no known domain (Duchaine et al., 2006), and ERI-5 is a tudor domain protein, which tethers the RdRP to Dicer (Thivierge et al., 2012). An additional genetic screen identified ERI-9 as an additional component of ERI/DCR complex acting in the endo-RNAi pathway (Pavelec et al., 2009). The miRNA pathway-dedicated complex involves interaction between Dicer and ALG-1/2 and, eventually, LIN-41 regulating let-7 miRNA (Duchaine et al., 2006). The list of Dicer-binding proteins in C. elegans is even longer and involves proteins with roles in different aspects of silencing or with yet undetermined functions (Beshore et al., 2009; Beshore et al., 2011; Duchaine et al., 2006; Racen et al., 2008).

\section{dsRBPs - RDE-4 and homologs}

RDE-4 is a dsRBP partner of Dicer in C. elegans. It is a 385-amino acid protein carrying two N-terminal dsRBDs and a third degenerate dsRBD at the C-terminus. A similar organization is found in other dsRBDs mentioned above - R2D2 and Loquacious in Drosophila and TRBP and PACT in mammals. RDE-4 was identified by a systematic screen for C. elegans RNAi-deficient mutants (Tabara et al., 1999). The $r d e-4$ mutant was completely deficient in RNAi but failed to show any discernible phenotype, including the absence of transposon activation, which was observed in some other $r d e$ mutants (Tabara et al., 1999). The loss of RDE-4 function can be compensated with injection of synthetic siRNA (Parrish and Fire, 2001) or with high amounts of dsRNA and siRNAs (Habig et al., 2008).

Mutants and biochemical analyses support a model where RDE-4 dimerizes through the C-terminal domain; dimers cooperatively bind long dsRNA, interacts with Dicer through the linker region, and forms a complex initiating the RNAi together with Dicer, RDE-1, and DRH-1/2 (Blanchard et al., 2011; Chiliveri and Deshmukh, 2014; Parker et al., 2006; Parker et al., 2008; Parrish and Fire, 2001; Tabara et al., 2002). The presence of an Argonaute protein in the complex suggests that in exo-RNAi, dsRNA recognition, processing into siRNA and loading of the Argonaute-containing effector complex is integrated in a one complex. Importantly, while RDE-4 is involved in siRNA production from exogenous and endogenous dsRNAs, RDE4, Dicer, RDE-1 and DRH-1/2 act in the exo-RNAi (Lee et al., 2006). The endogenous RNAi pathway (endo-RNAi), which targets endogenous genes, employs a distinct mechanism of siRNA production involving DCR-1 and RDE-4 but not RDE-1 and DRH-1/2 (Gent et al., 2010; Lee et al., 2006).

Importantly, RDE-4 differs from TARBP2 role in RNAi. While RDE-4 is involved in siRNA production from dsRNA but is not essential for later steps of RNAi because RDE4 immunoprecipitates with trigger dsRNA but not siRNA (Tabara et al., 2002), TARBP2 functions during RISC formation and AGO loading. Binding properties in vitro correspond to different roles of the two proteins in vivo. RDE-4 preferentially binds long dsRNA, while 
TRBP binds siRNA with an affinity that is independent of dsRNA length (Parker et al., 2008). This stems from the fact that RDE-4 binds cooperatively, via contributions from multiple domains, while TRBP binds non-cooperatively (Parker et al., 2008).

\section{Argonaute proteins}

Caenorhabditis has the largest diversity of Argonaute proteins of all studied model systems $-25-27$ Argonaute family members (Table 1 ) were described to carry primary and secondary small RNAs that act in soma and germline in multiple inter-related pathways (Buck and Blaxter, 2013; Yigit et al., 2006) (Arabidopsis, which has complex RNA silencing has 10 Argonaute proteins (reviewed in Buck and Blaxter, 2013). In addition to the above-described AGO and PIWI clades of the Argonaute family, nematodes utilize a unique Argonaute subfamily termed WAGO, which are "Worm-specific AGO" proteins, which bind secondary 22G small RNAs (summarized in (Buck and Blaxter, 2013). The complete description of small RNA pathways in C. elegans is beyond the scope of this report. Here, I will mainly focus on Argonaute proteins acting as the primary recipients of Dicer-generated small RNAs and will include the downstream pathways when directly related to the miRNA pathway or dsRNA response.

\section{ALG-1/2 - miRNA-binding Argonaute proteins}

There are two Argonaute proteins carrying canonical miRNAs in C. elegans: ALG-1 and ALG-2 (collectively designated ALG-1/2). They were identified as RDE-1 homologs, which cause heterochronic phenotypes similar to lin-4 and let-7 mutations and which are (together with $d c r-1$ ) necessary for the maturation and activity of the lin-4 and let-7 miRNAs. (Grishok et al., 2001). ALG-1/2 are required for the miRNA function, but not for the siRNA-directed gene silencing (Jannot et al., 2008). Although ALG-1 and ALG-2 are almost identical and highly redundant (only loss of both genes leads to embryonic lethality), several non-redundant functions have been observed in processing pre-miRNA processing/ miRISC formation (Kuzuoglu-Oeztuerk et al., 2012; Steiner et al., 2007; Tops et al., 2006; Vasquez-Rifo et al., 2012). Furthermore, while ALG-1/2 spatio-temporal expression profiles overlap, there is variability in dominating ALG expression in various cells and differential association to specific miRNAs (Vasquez-Rifo et al., 2012).

Interestingly, ALG- $1 / 2$ have conserved key residues for the slicing activity suggesting that they might function as active slicers despite the general lack of miRNA-mediated site-specific cleavage of cognate mRNAs. In any case, the slicing activity of ALG-1/2 has been demonstrated in vitro and in vivo (Bouasker and Simard, 2012). The loss of the slicing activity results in the accumulation of truncated miRNA precursors and altered miRISC formation suggesting that the slicing activity is necessary during miRISC formation (Bouasker and Simard, 2012). This notion is further supported by mutations in ALG-1, which separate miRISC loading and repression of cognate RNAs (Zinovyeva et al., 2014)

Canonical miRNA-mediated repression involves AIN-1 (ALG-1 INteracting protein), GW182 homolog, which interacts with miRISC and has been implicated in targeting 
Table 1 Argonaute proteins in Caenorhabditis elegans

The table was compiled form the following literature (Batista et al., 2008; Buckley et al., 2012; Fischer et al., 2011; Fischer et al., 2013; Tijsterman et al., 2002a; Tijsterman et al., 2002b; Vasale et al., 2010; Wang and Reinke, 2008; Yigit et al., 2006). Slicer activity "+" indicates that a given Argonaute protein has potential to act as a slicer, not that slicing is its primary mode of action. In some case, slicing potential has been inferred from the sequence, i.e. it is not supported with experimental evidence

\begin{tabular}{|c|c|c|c|c|c|c|c|}
\hline \multirow{2}{*}{ common name(s) } & \multirow{2}{*}{ subfamily } & \multirow{2}{*}{ slicer } & \multicolumn{5}{|c|}{ associated small RNA } \\
\hline & & & type & length & 5' nt & 5 ' end & 3' end \\
\hline ALG-1, F48F7.1 & $\mathrm{AGO}$ & + & miRNA & $22-23$ & & mono-P & $-\mathrm{OH}$ \\
\hline ALG-2 & $\mathrm{AGO}$ & + & miRNA & $22-23$ & & mono-P & $-\mathrm{OH}$ \\
\hline ALG-3, T22B3.2 & $\mathrm{AGO}$ & $+?$ & 26G siRNA & 26 & G & mono-P & $-\mathrm{OH}$ \\
\hline ALG-4, ZK757.3 & $\mathrm{AGO}$ & $+?$ & 26G siRNA & 26 & G & mono-P & $-\mathrm{OH}$ \\
\hline RDE-1, K08H10.7 & $\mathrm{AGO}$ & + & primary siRNA & $22-23$ & & mono-P & $-\mathrm{OH}$ \\
\hline ERGO-1, R09A1.1 & $\mathrm{AGO}$ & + & 26G siRNA & 26 & G & mono-P & 2'-O-met \\
\hline CSR-1, F20D12.1 & $\mathrm{AGO}$ & + & $22 \mathrm{G}$ siRNA & 22 & G & tri-P & $-\mathrm{OH}$ \\
\hline C06A1.4 & AGO? & - & & & & & \\
\hline H10D12.2, M03D4.6 & AGO? & - & & & & & \\
\hline C14B1.7 & PIWI? & - & & & & & \\
\hline T23D8.7, HPO-24 & PIWI? & - & & & & & \\
\hline C04F12.1 & PIWI? & $+?$ & & & & & \\
\hline PRG-1, D2030.6 & PIWI & + & $21 \mathrm{U}$ piRNA & 21 & $\mathrm{U}$ & mono-P & 2'-O-met \\
\hline PRG-2, C01G5.2 & PIWI & + & 21U piRNA & 21 & $\mathrm{U}$ & & \\
\hline WAGO-1, R06C7.1 & WAGO branch1 & - & $22 \mathrm{G}$ siRNA & 22 & G & tri-P & $-\mathrm{OH}$ \\
\hline WAGO-2, F55A12.1 & WAGO branch1 & - & $22 \mathrm{G}$ siRNA & 22 & G & tri-P & $-\mathrm{OH}$ \\
\hline $\begin{array}{l}\text { PPW-2, WAGO-3, } \\
\text { Y110A7A.18 }\end{array}$ & WAGO branch1 & - & 22G siRNA & 22 & G & tri-P & $-\mathrm{OH}$ \\
\hline WAGO-4, F58G1.1 & WAGO branch 1 & - & $22 \mathrm{G}$ siRNA & 22 & G & tri-P & $-\mathrm{OH}$ \\
\hline WAGO-5, ZK1248.7 & WAGO branch1 & - & 22G siRNA & 22 & G & tri-P & $-\mathrm{OH}$ \\
\hline $\begin{array}{l}\text { SAGO-2, WAGO-6/8, } \\
\text { F56A6.1 }\end{array}$ & WAGO branch2 & - & 22G siRNA & 22 & G & tri-P & $-\mathrm{OH}$ \\
\hline $\begin{array}{l}\text { PPW-1, WAGO-7, } \\
\text { C18E3.7 }\end{array}$ & WAGO branch2 & - & 22G siRNA & 22 & G & tri-P & $-\mathrm{OH}$ \\
\hline $\begin{array}{l}\text { SAGO-1, WAGO-8/6, } \\
\text { K12B6.1 }\end{array}$ & WAGO branch2 & - & $22 \mathrm{G}$ siRNA & 22 & G & tri-P & $-\mathrm{OH}$ \\
\hline $\begin{array}{l}\text { HRDE-1, WAGO-9, } \\
\text { C16C10.3 }\end{array}$ & WAGO branch 3 & - & 22G siRNA & 22 & G & tri-P & $-\mathrm{OH}$ \\
\hline WAGO-10, T22H9.3 & WAGO branch 3 & - & 22G siRNA & 22 & G & tri-P & $-\mathrm{OH}$ \\
\hline WAGO-11, Y49F6A.1 & WAGO branch 3 & - & 22G siRNA & 22 & G & tri-P & $-\mathrm{OH}$ \\
\hline $\begin{array}{l}\text { NRDE-3, WAGO-12, } \\
\text { R04A9.2 }\end{array}$ & WAGO branch 3 & - & 22G siRNA & 22 & G & tri-P & $-\mathrm{OH}$ \\
\hline
\end{tabular}


ALG-1 to P-bodies (Ding et al., 2005; Ding and Grosshans, 2009). It was reported that has lin-4-mediated repression acts at the level of translation initiation and frequently but not always coincides with transcript degradation (Ding and Grosshans, 2009). Remarkably, despite AIN-1/2 (two redundant GW182 homologs (Zhang et al., 2007)) lack most of the domains found in vertebrate proteins, they still interact with ALG-1/2 (Kuzuoglu-Oeztuerk et al., 2012). The interaction is mediated by GW repeats in the central part of AIN-1/2 but only AIN-1 interacts with PABPC1, PAN3, NOT1 and NOT2 (Kuzuoglu-Oeztuerk et al., 2012).This implies that the key principle of miRNA mediated repression, GW182-mediated tethering of PABPC1 and deadenylase complexes to AGO, is broadly conserved across metazoa.

The key determinant of target recognition is the seed binding as described in the mammalian section. Direct probing of the RNA backbone in isolated native C. elegans miRISC that the seed region is uniquely constrained, while the rest of the microRNA structure is conformationally flexible. Probing the Watson-Crick edges of the bases shows that bases 2-4 are largely inaccessible to solvent, while seed region bases $5-8$ are readily modified (Lambert et al., 2011). These data are consistent with structural analyses of AGO proteins in mammals and elsewhere.

\section{RDE-1 - primary siRNA-binding Argonaute in exo-RNAi and antiviral RNAi}

RDE-1 has the central role in RNAi. It was identified through a screen for RNA-deficient mutants (Tabara et al., 1999). Rde-1 mutants are strongly resistant to RNAi but without obvious defects in growth or development (Tabara et al., 1999). As mentioned above, RDE-1 associates with RDE-4, Dicer and DRH1/2 acting in the exo-RNAi and antiviral RNAi (Lu et al., 2005; Parrish and Fire, 2001; Tabara et al., 2002; Wilkins et al., 2005). As mentioned above, RDE-1 accommodates perfect siRNA duplexes, which includes artificially modified miRNA precursors (Steiner et al., 2007). It was proposed that RDE-1 functions as a scavenger taking up small RNAs from different sources (unlike ALG-1/2), which exclusively bind miRNAs (Correa et al., 2010).

Interestingly, the bulk of the slicing activity in C. elegans extracts in vitro comes from CSR-1 loaded with secondary 22G RNAs and not from RDE-1 loaded with primary siRNA (Aoki et al., 2007). While RDE-1 is a "slicer", it uses its endonucleolytic activity for removal of the passenger strand of the siRNA duplex and not for cleaving cognate RNAs, suggesting uncoupled roles of the RDE-1 slicer activity in siRNA maturation from and cognate RNA cleavage (Steiner et al., 2009). It was found that RDE-1 recruits RDE8 endoribonuclease to target RNA (Tsai et al., 2015). According to the model, RDE-8 cleaves cognate RNAs and is needed for the production of 3' uridylated fragments of target mRNA, which provide templates for RdRP-mediated production of secondary siRNAs (Tsai et al., 2015).

Taken together, RDE-1 loaded with primary siRNAs stands at the beginning of an amplification cascade, while other Argonaute proteins loaded with secondary siRNAs mediate downstream silencing (Yigit et al., 2006). A remarkable feature of the downstream AGOs loaded with $22 \mathrm{G}$ siRNAs is the lack the slicer activity. RDE-1 does not initiate only post-transcriptional repression; it has also been implicated in initiation (but not 
maintenance) of long-term silencing ( $>25$ generations) induced by long dsRNA in neurons (Buckley et al., 2012).

\section{G Argonaute effectors in RNAi - ERGO-1 - primary 26G siRNA-binding Argonaute in endo-RNAi}

ERGO-1 is a PIWI-clade effector that binds 26G RNAs generated in the endo-RNAi pathway in female germline and embryo (Gent et al., 2010; Pavelec et al., 2009; Vasale et al., 2010). ERGO-1 targets exhibit a non-random distribution in the genome and appear to include many gene duplications, suggesting that this pathway may control overexpression resulting from gene expansion (Vasale et al., 2010). In endo-RNAi in the soma, ERGO-1 accommodates $26 \mathrm{G}$ small RNAs in a process involving the ERI/Dicer complex and leading to production of more abundant secondary 22G small RNAs (Duchaine et al., 2006; Gent et al., 2009; Han et al., 2009). The biogenesis of primary 26G RNAs involves RdRP RRF-3 and RDE-4 while the biogenesis of secondary $22 \mathrm{G}$ siRNAs involves a second RdRP (RRF1 or EGO-1) and loading on WAGOs. Additional proteins implicated in ERGO-1-mediated repression include the helicase ERI-6/7 (Armitage helicase homolog) (Fischer et al., 2011), MUT-2, MUT-7, MUT-16 (Zhang et al., 2011), and RDE10/RDE-11 complex (Zhang et al., 2012), and RDE-12 (Shirayama et al., 2014).

\section{CSR-1 - secondary 22G siRNA-binding Argonautes}

The "executive arm" of RNAi in C. elegans are secondary 22G RNAs. One of the proteins binding 22G RNAs is CSR-1, which was identified in in vitro experiments with $C$. elegans lysates as a dominant slicer activity. However, CSR-1 was shown to rather associate with chromatin to promote proper organization or assembly of targets within the holocentric chromosomes (Campbell and Updike, 2015; Cecere et al., 2014; Claycomb et al., 2009; Seth et al., 2013; Tu et al., 2015; Wedeles et al., 2013a, b). CSR-1 22G RNAs are produced in the germline by a complex of DRH-3 (helicase), EKL-1 (tudor protein), and EGO-1 (RdRP) similarly to WAGO 22G RNAs, which utilize RRF-1 RdRP (Claycomb et al., 2009).

\section{WAGO proteins - secondary 22G siRNA-binding Argonautes}

WAGO proteins are loaded with $22 \mathrm{G}$ RNAs, which were produced by RdRPs. They represent secondary effectors, which execute silencing in slicer-independent fashion in the soma and/or germline in the cytoplasm and the nucleus. NRDE-3 and HRDE-1 were identified as WAGO proteins mediating nuclear silencing (Allo and Kornblihtt, 2010; Buckley et al., 2012; Burton et al., 2011; Gent et al., 2010). HRDE-1 has been implicated in initiation and maintenance of long-term silencing ( $>25$ generations) induced by long dsRNA in neurons (Buckley et al., 2012; Burton et al., 2011). For example, WAGO-1 silences genes, transposons, pseudogenes, and cryptic loci at the chromatin level by directing H3K27me3 through the NRDE pathway (Mao et al., 2015) and possibly in some association with components of the nonsense-mediated decay (NMD) (Gu et al., 2009). A C. elegans isolate from Hawaii 
had a natural defect in RNAi that was specific to the germline and was a result of multiple mutations the WAGO protein PPW-1 (Tijsterman et al., 2002b).

\section{RdRPs}

C. elegans is the main animal model for studying RdRPs. While an earlier study of RdRP in C. elegans suggested that dsRNA synthesis can be primed by primary siRNAs (a model of "degradative PCR") (Sijen et al., 2001), later studies demonstrated that RdRPs do not require the priming by primary siRNAs and produce short RNAs using RISC-targeted mRNAs as templates (Pak and Fire, 2007; Sijen et al., 2007). Surprisingly, sequencing of small RNAs associated with ongoing RNAi in C. elegans showed that Dicer-independent secondary siRNAs constitute the majority of cloned siRNAs (Pak and Fire, 2007). These secondary siRNAs are only antisense, carry 5' di- or triphosphates, and are not bound by RDE-1 but by other Argonaute proteins (Pak and Fire, 2007; Sijen et al., 2007). C. elegans genome four putative RdRPs, three of which were implicated in RNA silencing (Duchaine et al., 2006; Lee et al., 2006; Sijen et al., 2001; Smardon et al., 2000).

Of the three RdRPs, RRF-3 was implicated in the upstream part of RNAi, i.e. production of primary 26G siRNAs associated with ERGO-1 or ALG-3/4 Argonaute proteins (Conine et al., 2010; Conine et al., 2013; Duchaine et al., 2006; Gent et al., 2010; Gent et al., 2009; Han et al., 2009; Pavelec et al., 2009; Vasale et al., 2010) while EGO-1 and RRF-1 produce 22 G RNAs (Duchaine et al., 2006; Gent et al., 2010; Gent et al., 2009; Han et al., 2009; Jose et al., 2011; Pavelec et al., 2009; Vasale et al., 2010).

\section{miRNA pathway-specific features in nematodes}

C. elegans was the first organism, in which the first miRNA (lin-4) was identified (Lee et al., 1993) and which revealed that a conserved let-7 miRNA is conserved up to humans (Pasquinelli et al., 2000; Reinhart et al., 2000). The first two miRNAs were identified as regulators of developmental timing Remarkably, phenotype of $d c r-1$ mutants is similar to those of lin-4 and let-7 mutants (Grishok et al., 2001; Ketting et al., 2001; Knight and Bass, 2001) suggesting that miRNAs are the main Dicer product in C. elegans and that lin-4 and let-7 are functionally among the most significant miRNAs of the 434 annotated C. elegans mature miRNAs. C. elegans also produces non-canonical miRNAs, such as mirtrons (Ruby et al., 2007). High throughput analyses provided estimates of $\sim 3500-5000$ of binding sites bound by miRNAs in C. elegans (Zhang et al., 2007; Zisoulis et al., 2010).

C. elegans miRNAs are exposed to different regulations, some of which are also found in other model systems - this includes regulation of let-7 by LIN-28 and sequence uridylation (Lehrbach et al., 2009; Morita and Han, 2006; Newman et al., 2008; Ouchi et al., 2014; Stefani et al., 2015; Vadla et al., 2012; Van Wynsberghe et al., 2011), regulation of let-7 by RACK1 (Chu et al., 2014), and miRNA turnover by XRN-2 (Chatterjee and Grosshans, 2009) and DCS-1-XRN-1 complex (Bossé et al, 2013). miRNA-mediated repression is further regulated at the cellular level by autophagy (Zhang and Zhang, 2013) and 
other regulatory factors, such as the Golgi-associated retrograde protein (GARP) complex (Vasquez-Rifo et al., 2013). At the same time, specific miRNAs influence other RNA silencing pathways - they may interfere with RNAi (Massirer and Pasquinelli, 2013) or direct siRNA biogenesis (Correa et al., 2010).

\section{RNAi pathway-specific features in nematodes}

As it could be expected from diversity of factors mentioned above, RNAi in C. elegans is complex - different variants of RNAi operate in the germline and soma, RNAi recognizes different substrates and has a sequential production of small RNAs, which are the main executors of RNAi. RNAi in C. elegans has two "flavors" - endo-RNAi and exo-RNAi.

\section{Endogenous RNAi in the germline and soma}

The role of endogenous RNAi in shaping the transcriptomes of protein-coding genes during development has been challenged by mutant worms and flies lacking essential components of the RNAi pathway, which were viable and produced healthy offspring (Lee et al., 2004; Okamura et al., 2004; Tabara et al., 1999). Because of that, RNAi had been viewed as a defense mechanism against invasive nucleic acids. However, deep sequencing analyses revealed that endo-siRNAs with sequence complementarity to hundreds of protein-coding mRNAs are present in C. elegans (Ambros et al., 2003; Ruby et al., 2006). Endo-RNAi contributes to control of gene expression. This was revealed by microarray analysis of mutant worms lacking various RNAi-related factors, which found non-overlapping sets of differentially expressed genes, supporting the idea of multiple functionally distinct RNAi pathways in nematodes (Lee et al., 2006). At the same time, the multiple functionality also brings competition between small RNA pathways, which are manifested in different mutants - e.g. endo-siRNA mutants have increased expression of miRNA-regulated stage-specific developmental genes (Zhuang and Hunter, 2012).

Endo-RNAi pathway is initiated by endogenous dsRNAs, which are processed into primary siRNAs (26G RNAs associated with ERGO-1). Their biogenesis involves RDE-4, ERI-1/3/5/9, and RdRP RRF-3. Primary 26G RNAs recognize their targets, leading to production of secondary $22 \mathrm{G}$ RNAs, which will be antisense to the target and represent the main repressive force of endo-RNAi. 22G RNA biogenesis involves EGO-1 and RRF-1 RdRPs, RNAs are loaded mainly on CSR-1 or WAGO proteins. Secondary siRNAs are generated by RdRPs thus serve as amplifiers of the endogenous RNAi in both soma and germline.

A number of endo-siRNA genes were identified in a genetic screen for factors silencing a multicopy transgene. They included genes required for siRNA biogenesis or stability in the oocyte-specific ERGO-1 pathway, including eri-12, encoding an interactor of the RNAi-defective protein RDE-10, and ntl-9/CNOT9, one of several identified CCR4-NOT complex genes, and a conserved ARF-like small Cell ARL-8 required for primary siRNA biogenesis or stability in the sperm-specific ALG-3/4 endogenous RNAi pathway (Fischer et al., 2013). Additional studies revealed that mutations in RNAi-related genes, result in 
defects in meiotic chromosome disjunction, spindle formation or microtubule organization during sperm development and ultimately lead to male sterility or embryonic lethality of the offspring (Gent et al., 2009; Han et al., 2009; Han et al., 2008; Pavelec et al., 2009).

In search for the cellular and developmental processes, which might be controlled by endo-siRNAs in C. elegans, spermatogenesis-associated genes were found enriched in the group of transcripts matching endo-siRNAs (Ruby et al., 2006). Analysis of endo-siRNA target suggested a difference between primary and secondary endo-siRNA targets as 18to 22-mer siRNAs associated with genes required for embryonic development, 23-mers associated uniquely with post-embryonic development, and 24-26-mers associated with phosphorus metabolism or protein modification (Asikainen et al., 2008). It was also shown that in oocytes and embryos, ERGO-1-associated 26G siRNAs and NRDE-3-associated $22 \mathrm{G}$ siRNAs silence recently duplicated genes (Fischer et al., 2011; Vasale et al., 2010).

\section{Exogenous RNAi-systemic and environmental}

Exo-RNAi is triggered by exogenous dsRNA, which can come in many forms; RNAi in C. elegans can be triggered by injecting dsRNA essentially anywhere in the animal, soaking the animal in dsRNA solution or even by feeding it bacteria expressing long dsRNA (Tabara et al., 1998). This allows not only experimental manipulations in the lab but also target parasitic nematodes by creating nematode resistant plants (Yang et al., 2013). However, there is a heterogeneity in the nature in the presence of non-cell autonomous RNAi. For example, only one of eight tested Caenorhabditis species showed efficient environmental RNAi (Winston et al., 2007). Remarkably, RNAi also operates in zero gravity in space (Etheridge et al., 2011). It has zero significance for the report, but worth of mentioning.

The spreading of the silencing signal among cells is controlled by dsRNA-transporting channels encoded by sid-1 and sid-2 genes, which were identified in forward genetic screen to be responsible for systemic RNAi in C. elegans (Winston et al., 2002). SID-1 (systemic RNAi deficient-1) is a conserved transmembrane protein that forms a dsRNA channel (Feinberg and Hunter, 2003; Shih et al., 2009; Shih and Hunter, 2011). Sid-1 has homologs in a wide range of animals, including mammals. Sid-1 mutants have intact cell autonomous RNAi, but cannot perform neither systemic RNAi nor environmental RNAi in response to feeding, soaking, or injection of dsRNA (Winston et al., 2002). SID-2 is a transmembrane protein localized to an apical membrane of intestinal cells. It is necessary for the initial import of dsRNA from gut lumen, but not for the systemic spread of silencing signals among cells (McEwan et al., 2012). Sid-2 homologs have been identified only in two other Caenorhabditis species (Winston et al., 2007). SID-3 is a conserved tyrosine kinase required for the efficient import of dsRNA. Without SID-3, cells perform RNA silencing well but import dsRNA poorly (Jose et al., 2012). The next and distinct systemic RNAi SID factor is SID-5 (SID-4 does not exist), an endosome-associated protein, which promotes transport of RNA silencing signals between cells and act differently than SID1-3 (Hinas et al., 2012). Remarkably, SID-1 sensitizes Drosophila and silkworm cells to RNAi induced by soaking by enabling concentration-dependent cellular uptake of dsRNA (Feinberg and Hunter, 2003; Shih et al., 2009) (Mon et al., 2012; Mon et al., 2013; Shih and Hunter, 2011; Xu et al., 2013a; Xu et al., 2013b). 
In cells, exo-RNAi involves the above-mentioned RDE-4/Dicer/DRH-1 complex in processing dsRNA into primary siRNAs, which are loaded on RDE-1 Argonaute protein. RDE-1 itself does not cleave cognate RNAs. Instead, it recruits RDE-ribonuclease, which is involved in production of templates for RdRP-mediated production of secondary siRNAs (Tsai et al., 2015). In addition, genetic, proteomic, and biochemical data suggested that downstream of RDE-1 operates RDE-10/RDE-11 complex, which is recruited for degradation of target mRNA and RRF-1-dependent secondary siRNA synthesis (Zhang et al., 2012). The link between the RDE-10/RDE-11 complex and the aforementioned RDE- 8 nuclease is unknown at the moment. Finally, several negative regulators of exo-RNAi were identified in genetic screens, including the ERI-1 nuclease (Kennedy et al., 2004), the ERI2/RRF-3 RdRP (Simmer et al., 2002), ERI-3 (Duchaine et al., 2006), ERI-9, and the Argonaute ERI-8/ERGO-1 (Pavelec et al., 2009).

\section{Antiviral RNAi}

RNAi functions as an antiviral defense in C. elegans. This role of RNAi was experimentally addressed even though endogenous viral pathogens of $C$. elegans were unknown. The problem of absenting endogenous C. elegans viruses was bypassed by using an "artificial" infection with viruses, which had a broad host range and could infect $C$. elegans under laboratory conditions. Model viral infections were based on the $(+)$ ssRNA flock house virus (FHV) (Lu et al., 2005) or the (-)ssRNA vesicular stomatitis virus (VSV) (Schott et al., 2005; Wilkins et al., 2005). Infection with the recombinant VSV was augmented in strong RNAi mutant animals ( $r d e-1$ and $r d e-4)$, which produced higher viral titers. Furthermore, VSV infection was attenuated in $r r f-3$ and eri-1 mutants that are hypersensitive to RNAi (Wilkins et al., 2005). Similar results were obtained from infected cultured cells (Schott et al., 2005) and FHV infection of rde-1 mutants (Lu et al., 2005). Not surprisingly, genes misregulated in C. elegans deficient in Dicer, RDE-4, or RDE-1 are enriched for innate immunity genes (Welker et al., 2007). Antiviral RNAi involves also other genes, such as $r s d-2$ (RNAi spreading defective 2), which was implicated in secondary viral siRNA biogenesis in RDE-4 independent manner (Guo et al., 2013b).

The antiviral role of exo-RNAi was subsequently confirmed in a natural viral infection of C. elegans and C. briggsae by Orsay virus (Felix et al., 2011). Analysis of gene expression in $C$. elegans infected with Orsay virus revealed competition of the antiviral response with endogenous small RNA pathways, which was manifested as redirection of RDE-1 from its endogenous small RNA cofactors, leading to loss of repression of endogenous RDE-1 targets and reduction of miRNA levels and an up-regulation of their target genes (Sarkies et al., 2013). Interestingly, genome-wide association study in C. elegans wild populations identified as a major determinant of viral sensitivity DRH-1, the aforementioned RIG-1 homolog (Ashe et al., 2013). Similarly, a genetic analysis revealed an essential role for both DRH-1 and DRH-3 in antiviral RNAi (Guo et al., 2013a). DRH-3 is another Dicer-RIG-I family protein that is essential for RNA silencing and germline development (Nakamura et al., 2007). DRH-3 binds both single-stranded and double-stranded RNAs with high affinity. However, the ATPase activity of DRH-3 is stimulated only by double-stranded RNA (Matranga and Pyle, 2010). Analysis of DRH-1 and DRH-3 in infected 


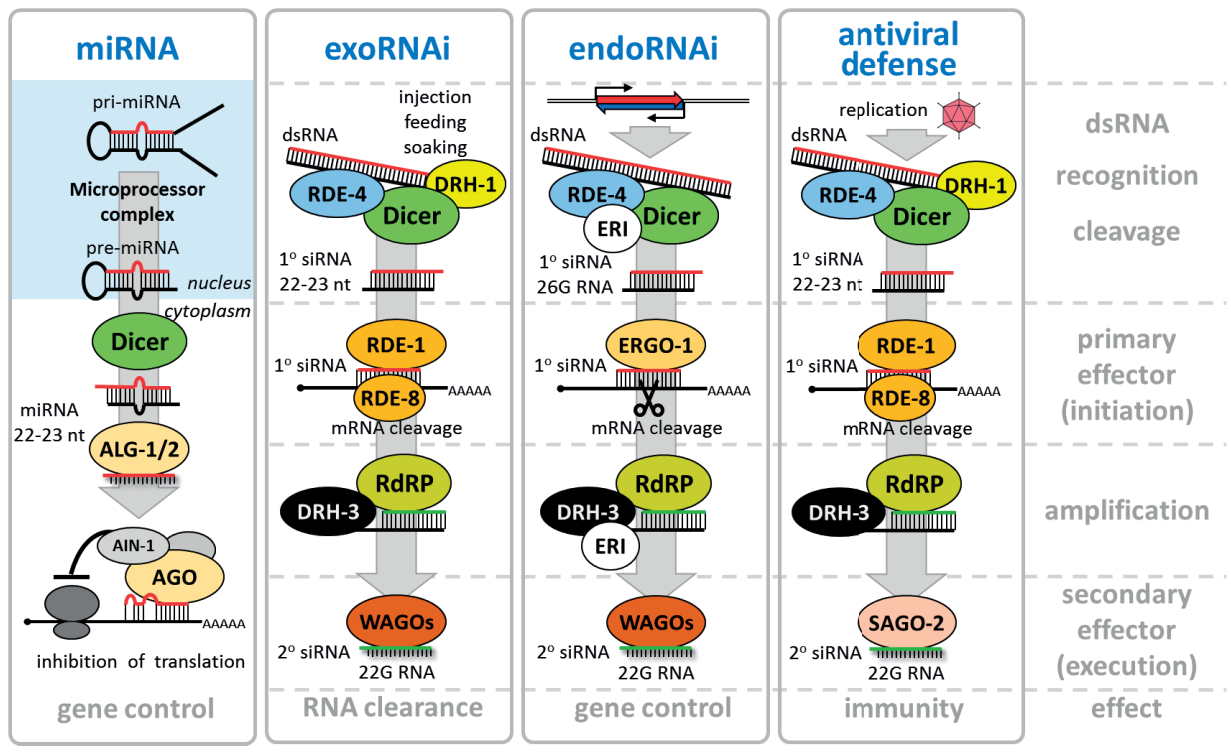

Figure 3 Schematic overview of reviewed small RNA pathways in C. elegans

worms suggested distinct roles where DRH-1 was involved in production of viral primary siRNAs, whereas DRH-3 is involved in biogenesis of 22 nt secondary siRNAs (Fitzgerald et al., 2014; Guo et al., 2013a) (Fig. 3). Taken together, RIG-I homologs function in innate immunity through evolution of Metazoa where they adapting to specific molecular mechanisms - primary and secondary siRNA biogenesis in RNAi in nematodes and stimulation of the interferon response in mammals.

Importantly, innate immunity operates beyond viruses and RNAi; Bacillus thuringiensis strain DB27 is virulent bacterium for C. elegans but not another nematode species. An analysis of virulence factors revealed that $d c r-1$ mutant alleles deficient in microRNA (miRNA) processing, but not those deficient only in RNAi, are resistant to $B$. thuringiensis DB27 (Iatsenko et al., 2013). This suggests that Dicer is a part of a system balancing small RNA pathways and antiviral immunity. This model is further extended with the miR-3541 family, regulates the efficiency of RNAi (Massirer and Pasquinelli, 2013). The loss of miR-35-41 results in enhanced exo-RNAi sensitivity and reduced endo-RNAi effectiveness suggesting that these miRNAs normally help balance the RNAi pathways (Massirer and Pasquinelli, 2013).

\section{Adenosine deamination}

A connection between A-to-I editing and RNAi has been revealed in C. elegans. A transcriptome-wide analysis of A-to-I editing sites identified as many as 664 editing-enriched regions, which represent the core of A-to-I editing substrates in C. elegans. Among the 
known substrates are mRNAs with hairpin structures in 3' UTRs; editing however does not necessarily prevent nuclear export and presence on polysomes (Hundley et al., 2008; Morse et al., 2002; Morse and Bass, 1999). Approximately 1.7\% of C. elegans mRNAs contained such editing-enriched regions (Whipple et al., 2015). A-to-I editing also affects small RNAs.

In contrast to mice, where the loss of A-to-I editing is lethal, in Drosophila and C. elegans Adar null phenotype causes only weak phenotypic alterations (Palladino et al., 2000; Tonkin and Bass, 2003; Tonkin et al., 2002). Importantly, $a d r-1$ or $a d r-2$ mutant worms exhibit a defective chemotaxis but the phenotype is reverted when worms lacking Adar are crossed with RNAi-defective strains (Tonkin and Bass, 2003). Analysis of ADAR mutants showed that A-to-I editing affects microRNAs as well as 26G endo-siRNAs (Warf et al., 2012). That ADAR and RNAi pathways are competing for common targets is supported by common loci from which originate edited transcripts and in which are found RNAi-dependent short RNAs upregulated in ADAR mutants (Wu et al., 2011).

\section{Summary}

The principles of primary and secondary small RNA production adopted during C. elegans evolution provide an explanation how such a complex of small RNA pathway can rely on a single Dicer protein. The key apparently lies in structural differences among Dicer substrates, Dicer co-factors facilitating loading onto correct Argonaute proteins, and cognate RNAs (targeted by primary small RNA), which serve as templates for secondary small RNAs. Given the complexity of the Nematode phylum, one could ask how representative is C. elegans model of the phylum. There has been a survey for orthologs of 77 C. elegans RNAi pathway proteins in 13 nematode species, which revealed that while proteins responsible for uptake and spread of exogenously applied dsRNA are absent from parasitic species. Furthermore, Argonaute proteins regulating gene expression but not exo-RNAi Argonautes are broadly conserved; secondary Argonautes (SAGO/WAGO) are poorly conserved, and the nuclear AGO NRDE-3 was not identified in any parasite (Dalzell et al., 2011). Taken together, Caenorhabditis possess an expanded RNAi effector repertoire relative to the parasitic nematodes while all nematode species displayed qualitatively similar coverage of functional protein groups (Dalzell et al., 2011).

\section{Acknowledgement}

I would like to thank my colleagues Jan Paces, Miloslav Nic and Tomas Novotny for help with collecting literature for the review. The review content was produced under a contract OC/EFSA/GMO/2015/01-CT 01 with European Food Safety Authority (EFSA); the opinions expressed are those of the contractor only and do not represent EFSA's official position. Publication of the review was funded by LO1220 and LM2015063 by the Ministry of Education, Youth and Sports. 


\section{References}

Allo, M., and Kornblihtt, A.R. (2010). Gene Silencing: Small RNAs Control RNA Polymerase II Elongation. Current Biology 20, R704-R707.

Ambros, V., Lee, R.C., Lavanway, A., Williams, P.T., and Jewell, D. (2003). MicroRNAs and other tiny endogenous RNAs in C-elegans. Current Biology 13, 807-818.

Aoki, K., Moriguchi, H., Yoshioka, T., Okawa, K., and Tabara, H. (2007). In vitro analyses of the production and activity of secondary small interfering RNAs in C-elegans. EMBO J 26, 5007-5019.

Ashe, A., Bélicard, T., Le Pen, J., Sarkies, P., Frézal, L., Lehrbach, N.J., Félix, M.A., and Miska, E.A. (2013). A deletion polymorphism in the Caenorhabditis elegans RIG-I homolog disables viral RNA dicing and antiviral immunity. Elife 2013.

Asikainen, S., Heikkinen, L., Wong, G., and Storvik, M. (2008). Functional characterization of endogenous siRNA target genes in Caenorhabditis elegans. BMC Genomics 9, 270-270.

Batista, P.J., Ruby, J.G., Claycomb, J.M., Chiang, R., Fahlgren, N., Kasschau, K.D., Chaves, D.A., Gu, W., Vasale, J.J., Duan, S., et al. (2008). PRG-1 and 21U-RNAs interact to form the piRNA complex required for fertility in C-elegans. Molecular Cell 31, 67-78.

Beshore, E.L., McEwen, T., Marshall, J., and Bennett, K. (2009). Activating interactions between GLH-1, microRNAs and Dicer in C. elegans. Developmental Biology 331, 418-418.

Beshore, E.L., McEwen, T.J., Jud, M.C., Marshall, J.K., Schisa, J.A., and Bennett, K.L. (2011). C. elegans Dicer interacts with the P-granule component GLH-1 and both regulate germline RNPs. Developmental Biology 350, 370-381.

Blanchard, D., Parameswaran, P., Lopez-Molina, J., Gent, J., Saynuk, J.F., and Fire, A. (2011). On the nature of in vivo requirements for rde-4 in RNAi and developmental pathways in C-elegans. RNA Biology 8, 458-467.

Bouasker, S., and Simard, M.J. (2012). The slicing activity of miRNA-specific Argonautes is essential for the miRNA pathway in C. elegans. Nucleic Acids Research 40, 10452-10462.

Buck, A.H., and Blaxter, M. (2013). Functional diversification of Argonautes in nematodes: an expanding universe. Biochemical Society Transactions 41, 881-886.

Buckley, B.A., Burkhart, K.B., Gu, S.G., Spracklin, G., Kershner, A., Fritz, H., Kimble, J., Fire, A., and Kennedy, S. (2012). A nuclear Argonaute promotes multigenerational epigenetic inheritance and germline immortality. Nature 489, 447-451.

Burton, N.O., Burkhart, K.B., and Kennedy, S. (2011). Nuclear RNAi maintains heritable gene silencing in Caenorhabditis elegans. Proceedings of the National Academy of Sciences of the United States of America 108, 19683-19688.

Campbell, A.C., and Updike, D.L. (2015). CSR-1 and P granules suppress sperm-specific transcription in the C. elegans germline. Development 142, 1745-1755.

Cecere, G., Hoersch, S., O’Keeffe, S., Sachidanandam, R., and Grishok, A. (2014). Global effects of the CSR-1 RNA interference pathway on the transcriptional landscape. Nature Structural \& Molecular Biology 21, 358-U394.

Chatterjee, S., and Grosshans, H. (2009). Active turnover modulates mature microRNA activity in Caenorhabditis elegans. Nature 461, 546-U120.

Chiliveri, S.C., and Deshmukh, M.V. (2014). Structure of RDE-4 dsRBDs and mutational studies provide insights into dsRNA recognition in the Caenorhabditis elegans RNAi pathway. Biochemical Journal 458, 119-130. 
Chu, Y.D., Wang, W.C., Chen, S.A.A., Hsu, Y.T., Yeh, M.W., Slack, F.J., and Chan, S.P. (2014). RACK-1 regulates let-7 microRNA expression and terminal cell differentiation in Caenorhabditis elegans. Cell Cycle 13, 1995-2009.

Claycomb, J.M., Batista, P.J., Pang, K.M., Gu, W.F., Vasale, J.J., van Wolfswinkel, J.C., Chaves, D.A., Shirayama, M., Mitani, S., Ketting, R.F., et al. (2009). The Argonaute CSR-1 and Its 22G-RNA Cofactors Are Required for Holocentric Chromosome Segregation. Cell 139, 123-134.

Conine, C.C., Batista, P.J., Gu, W.F., Claycomb, J.M., Chaves, D.A., Shirayama, M., and Mello, C.C. (2010). Argonautes ALG-3 and ALG-4 are required for spermatogenesis-specific 26G-RNAs and thermotolerant sperm in Caenorhabditis elegans. Proceedings of the National Academy of Sciences of the United States of America 107, 3588-3593.

Conine, C.C., Moresco, J.J., Gu, W., Shirayama, M., Conte, D., Jr., Yates, J.R., III, and Mello, C.C. (2013). Argonautes Promote Male Fertility and Provide a Paternal Memory of Germline Gene Expression in C. elegans. Cell 155, 1532-1544.

Correa, R.L., Steiner, F.A., Berezikov, E., and Ketting, R.F. (2010). MicroRNA-Directed siRNA Biogenesis in Caenorhabditis elegans. Plos Genetics 6, e1000903-e1000903.

Dalzell, J.J., McVeigh, P., Warnock, N.D., Mitreva, M., Bird, D.M., Abad, P., Fleming, C.C., Day, T.A., Mousley, A., Marks, N.J., et al. (2011). RNAi Effector Diversity in Nematodes. Plos Neglected Tropical Diseases 5, e1176-e1176.

Denli, A.M., Tops, B.B.J., Plasterk, R.H.A., Ketting, R.F., and Hannon, G.J. (2004). Processing of primary microRNAs by the Microprocessor complex. Nature 432, 231-235.

Ding, L., Spencer, A., Morita, K., and Han, M. (2005). The developmental timing regulator AIN-1 interacts with miRISCs and may target the argonaute protein ALG-1 to cytoplasmic P bodies in C. elegans. Molecular Cell 19, 437-447.

Ding, X.C., and Grosshans, H. (2009). Repression of C-elegans microRNA targets at the initiation level of translation requires GW182 proteins. EMBO J 28, 213-222.

Drake, M., Furuta, T., Suen, K.M., Gonzalez, G., Liu, B., Kalia, A., Ladbury, J.E., Fire, A.Z., Skeath, J.B., and Arur, S. (2014). A Requirement for ERK-Dependent Dicer Phosphorylation in Coordinating Oocyte-to-Embryo Transition in C. elegans. Developmental Cell 31, 614-628.

Duchaine, T.F., Wohlschlegel, J.A., Kennedy, S., Bei, Y.X., Conte, D., Pang, K.M., Brownell, D.R., Harding, S., Mitani, S., Ruvkun, G., et al. (2006). Functional proteomics reveals the biochemical niche of C-elegans DCR-1 in multiple small-RNA-mediated pathways. Cell 124, 343-354.

Etheridge, T., Nemoto, K., Hashizume, T., Mori, C., Sugimoto, T., Suzuki, H., Fukui, K., Yamazaki, T., Higashibata, A., Szewczyk, N.J., et al. (2011). The Effectiveness of RNAi in Caenorhabditis elegans Is Maintained during Spaceflight. Plos One 6, e20459-e20459.

Feinberg, E.H., and Hunter, C.P. (2003). Transport of dsRNA into cells by the transmembrane protein SID-1. Science 301, 1545-1547.

Felix, M.A., Ashe, A., Piffaretti, J., Wu, G., Nuez, I., Belicard, T., Jiang, Y., Zhao, G., Franz, C.J., Goldstein, L.D., et al. (2011). Natural and experimental infection of Caenorhabditis nematodes by novel viruses related to nodaviruses. Plos Biology 9, e1000586.

Fischer, S.E.J., Montgomery, T.A., Zhang, C., Fahlgren, N., Breen, P.C., Hwang, A., Sullivan, C.M., Carrington, J.C., and Ruvkun, G. (2011). The ERI-6/7 Helicase Acts at the First Stage of an siRNA Amplification Pathway That Targets Recent Gene Duplications. Plos Genetics 7, e1002369-e1002369. 
Fischer, S.E.J., Pan, Q., Breen, P.C., Qi, Y., Shi, Z., Zhang, C., and Ruvkun, G. (2013). Multiple small RNA pathways regulate the silencing of repeated and foreign genes in C. elegans. Genes \& Development 27, 2678-2695.

Fitzgerald, M.E., Vela, A., and Pyle, A.M. (2014). Dicer-related helicase 3 forms an obligate dimer for recognizing 22G-RNA. Nucleic Acids Research 42, 3919-3930.

Frezal, L., and Felix, M.A. (2015). C. elegans outside the Petri dish. Elife 4.

Gao, Z.Q., Wang, M., Blair, D., Zheng, Y.D., and Dou, Y.X. (2014). Phylogenetic Analysis of the Endoribonuclease Dicer Family. Plos One 9, e95350-e95350.

Ge, X., Zhao, X., Nakagawa, A., Gong, X.Q., Skeen-Gaar, R.R., Shi, Y., Gong, H.P., Wang, X.Q., and Xue, D. (2014). A novel mechanism underlies caspase-dependent conversion of the dicer ribonuclease into a deoxyribonuclease during apoptosis. Cell Research 24, 218-232.

Gent, J.I., Lamm, A.T., Pavelec, D.M., Maniar, J.M., Parameswaran, P., Tao, L., Kennedy, S., and Fire, A.Z. (2010). Distinct Phases of siRNA Synthesis in an Endogenous RNAi Pathway in C. elegans Soma. Molecular Cell 37, 679-689.

Gent, J.I., Schvarzstein, M., Villeneuve, A.M., Gu, S.G., Jantsch, V., Fire, A.Z., and Baudrimont, A. (2009). A Caenorhabditis elegans RNA-Directed RNA Polymerase in Sperm Development and Endogenous RNA Interference. Genetics 183, 1297-1314.

Grishok, A., Pasquinelli, A.E., Conte, D., Li, N., Parrish, S., Ha, I., Baillie, D.L., Fire, A., Ruvkun, G., and Mello, C.C. (2001). Genes and mechanisms related to RNA interference regulate expression of the small temporal RNAs that control C-elegans developmental timing. Cell 106, 23-34.

Gu, W.F., Shirayama, M., Conte, D., Vasale, J., Batista, P.J., Claycomb, J.M., Moresco, J.J., Youngman, E.M., Keys, J., Stoltz, M.J., et al. (2009). Distinct Argonaute-Mediated 22G-RNA Pathways Direct Genome Surveillance in the C. elegans Germline. Molecular Cell 36, 231-244.

Guo, X.Y., Zhang, R., Wang, J., Ding, S.W., and Lu, R. (2013a). Homologous RIG-I-like helicase proteins direct RNAi-mediated antiviral immunity in C. elegans by distinct mechanisms. Proceedings of the National Academy of Sciences of the United States of America 110, 16085-16090.

Guo, X.Y., Zhang, R., Wang, J., and Lu, R. (2013b). Antiviral RNA Silencing Initiated in the Absence of RDE-4, a Double-Stranded RNA Binding Protein, in Caenorhabditis elegans. Journal of Virology $87,10721-10729$.

Habig, J.W., Aruscavage, P.J., and Bass, B.L. (2008). In C. elegans, High Levels of dsRNA Allow RNAi in the Absence of RDE-4. Plos One 3, e4052-e4052.

Han, T., Manoharan, A.P., Harkins, T.T., Bouffard, P., Fitzpatrick, C., Chu, D.S., Thierry-Mieg, D., Thierry-Mieg, J., and Kim, J.K. (2009). 26G endo-siRNAs regulate spermatogenic and zygotic gene expression in Caenorhabditis elegans. Proceedings of the National Academy of Sciences of the United States of America 106, 18674-18679.

Han, W., Sundaram, P., Kenjale, H., Grantham, J., and Timmons, L. (2008). The Caenorhabditis elegans rsd-2 and rsd-6 genes are required for chromosome functions during exposure to unfavorable environments. Genetics 178, 1875-1893.

Hellwig, S., and Bass, B.L. (2008). A starvation-induced noncoding RNA modulates expression of Dicer-regulated genes. Proceedings of the National Academy of Sciences of the United States of America 105, 12897-12902.

Hinas, A., Wright, A.J., and Hunter, C.P. (2012). SID-5 Is an Endosome-Associated Protein Required for Efficient Systemic RNAi in C. elegans. Current Biology 22, 1938-1943. 
Hundley, H.A., Krauchuk, A.A., and Bass, B.L. (2008). C-elegans and H-sapiens mRNAs with edited 3 'UTRs are present on polysomes. RNA 14, 2050-2060.

Iatsenko, I., Sinha, A., Rodelsperger, C., and Sommer, R.J. (2013). New Role for DCR-1/Dicer in Caenorhabditis elegans Innate Immunity against the Highly Virulent Bacterium Bacillus thuringiensis DB27. Infection and Immunity 81, 3942-3957.

Jannot, G., Boisvert, M.E.L., Banville, I.H., and Simard, M.J. (2008). Two molecular features contribute to the Argonaute specificity for the microRNA and RNAi pathways in C-elegans. RNA 14, 829-835.

Jaskiewicz, L., and Filipowicz, W. (2008). Role of Dicer in posttranscriptional RNA silencing. Current topics in microbiology and immunology 320, 77-97.

Jose, A.M., Garcia, G.A., and Hunter, C.P. (2011). Two classes of silencing RNAs move between Caenorhabditis elegans tissues. Nature Structural \& Molecular Biology 18, 1183-U1111.

Jose, A.M., Kim, Y.A., Leal-Ekman, S., and Hunter, C.P. (2012). Conserved tyrosine kinase promotes the import of silencing RNA into Caenorhabditis elegans cells. Proceedings of the National Academy of Sciences of the United States of America 109, 14520-14525.

Kennedy, S., Wang, D., and Ruvkun, G. (2004). A conserved siRNA-degrading RNase negatively regulates RNA interference in C. elegans. Nature 427, 645-649.

Ketting, R.F., Fischer, S.E.J., Bernstein, E., Sijen, T., Hannon, G.J., and Plasterk, R.H.A. (2001). Dicer functions in RNA interference and in synthesis of small RNA involved in developmental timing in C-elegans. Genes \& Development 15, 2654-2659.

Knight, S.W., and Bass, B.L. (2001). A role for the RNase III enzyme DCR-1 in RNA interference and germ line development in Caenorhabditis elegans. Science 293, 2269-2271.

Kuzuoglu-Oeztuerk, D., Huntzinger, E., Schmidt, S., and Izaurralde, E. (2012). The Caenorhabditis elegans GW182 protein AIN-1 interacts with PAB-1 and subunits of the PAN2-PAN3 and CCR4NOT deadenylase complexes. Nucleic Acids Research 40, 5651-5665.

Lambert, N.J., Gu, S.G., and Zahler, A.M. (2011). The conformation of microRNA seed regions in native microRNPs is prearranged for presentation to mRNA targets. Nucleic Acids Research 39, 4827-4835.

Lee, R.C., Feinbaum, R.L., and Ambros, V. (1993). The C. elegans heterochronic gene lin-4 encodes small RNAs with antisense complementarity to lin-14. Cell 75, 843-854.

Lee, R.C., Hammell, C.M., and Ambros, V. (2006). Interacting endogenous and exogenous RNAi pathways in Caenorhabditis elegans. RNA 12, 589-597.

Lee, Y.S., Nakahara, K., Pham, J.W., Kim, K., He, Z., Sontheimer, E.J., and Carthew, R.W. (2004). Distinct roles for Drosophila Dicer-1 and Dicer-2 in the siRNA/miRNA silencing pathways. Cell 117, 69-81.

Lehrbach, N.J., Armisen, J., Lightfoot, H.L., Murfitt, K.J., Bugaut, A., Balasubramanian, S., and Miska, E.A. (2009). LIN-28 and the poly(U) polymerase PUP-2 regulate let-7 microRNA processing in Caenorhabditis elegans. Nature Structural \& Molecular Biology 16, 1016-U1027.

Lu, R., Maduro, M., Li, F., Li, H.W., Broitman-Maduro, G., Li, W.X., and Ding, S.W. (2005). Animal virus replication and RNAi-mediated antiviral silencing in Caenorhabditis elegans. Nature 436, 1040-1043.

Mao, H., Zhu, C.M., Zong, D.D., Weng, C.C., Yang, X.W., Huang, H., Liu, D., Feng, X.Z., and Guang, S.H. (2015). The Nrde Pathway Mediates Small-RNA-Directed Histone H3 Lysine 27 Trimethylation in Caenorhabditis elegans. Current Biology 25, 2398-2403. 
Margulis, L., and Schwartz, K.V. (1998). Five kingdoms : an illustrated guide to the phyla of life on earth, 3rd edn (New York: W.H. Freeman).

Massirer, K.B., and Pasquinelli, A.E. (2013). MicroRNAs that interfere with RNAi. Worm 2, e21835-e21835.

Matranga, C., and Pyle, A.M. (2010). Double-stranded RNA-dependent ATPase DRH-3 INSIGHT INTO ITS ROLE IN RNA SILENCING IN CAENORHABDITIS ELEGANS. Journal of Biological Chemistry 285, 25363-25371.

McEwan, D.L., Weisman, A.S., and Huntert, C.P. (2012). Uptake of Extracellular Double-Stranded RNA by SID-2. Molecular Cell 47, 746-754.

Mon, H., Kobayashi, I., Ohkubo, S., Tomita, S., Lee, J.M., Sezutsu, H., Tamura, T., and Kusakabe, T. (2012). Effective RNA interference in cultured silkworm cells mediated by overexpression of Caenorhabditis elegans SID-1. RNA Biology 9, 40-46.

Mon, H., Li, Z., Kobayashi, I., Tomita, S., Lee, J., Sezutsu, H., Tamura, T., and Kusakabe, T. (2013). Soaking RNAi in Bombyx mori BmN4-SID1 cells arrests cell cycle progression. Journal of Insect Science 13, 155-155.

Morita, K., and Han, M. (2006). Multiple mechanisms are involved in regulating the expression of the developmental timing regulator lin-28 in Caenorhabditis elegans. EMBO J 25, 5794-5804.

Morse, D.P., Aruscavage, P.J., and Bass, B.L. (2002). RNA hairpins in noncoding regions of human brain and Caenorhabditis elegans mRNA are edited by adenosine deaminases that act on RNA. Proceedings of the National Academy of Sciences of the United States of America 99, 7906-7911.

Morse, D.P., and Bass, B.L. (1999). Long RNA hairpins that contain inosine are present in Caenorhabditis elegans poly $(\mathrm{A})(+)$ RNA. Proceedings of the National Academy of Sciences of the United States of America 96, 6048-6053.

Nakagawa, A., Shi, Y., Kage-Nakadai, E., Mitani, S., and Xue, D. (2010). Caspase-Dependent Conversion of Dicer Ribonuclease into a Death-Promoting Deoxyribonuclease. Science 328, 327-334.

Nakamura, M., Ando, R., Nakazawa, T., Yudazono, T., Tsutsumi, N., Hatanaka, N., Ohgake, T., Hanaoka, F., and Eki, T. (2007). Dicer-related drh-3 gene functions in germ-line development by maintenance of chromosomal integrity in Caenorhabditis elegans. Genes to Cells 12, 997-1010.

Newman, M.A., Thomson, J.M., and Hammond, S.M. (2008). Lin-28 interaction with the Let-7 precursor loop mediates regulated microRNA processing. RNA 14, 1539-1549.

Okamura, K., Ishizuka, A., Siomi, H., and Siomi, M.C. (2004). Distinct roles for Argonaute proteins in small RNA-directed RNA cleavage pathways. Genes Dev 18, 1655-1666.

Ouchi, Y., Yamamoto, J., and Iwamoto, T. (2014). The Heterochronic Genes lin-28a and lin-28b Play an Essential and Evolutionarily Conserved Role in Early Zebrafish Development. Plos One 9, e88086-e88086.

Pak, J., and Fire, A. (2007). Distinct populations of primary and secondary effectors during RNAi in C-elegans. Science 315, 241-244.

Palladino, M.J., Keegan, L.P., O’Connell, M.A., and Reenan, R.A. (2000). A-to-I pre-mRNA editing in Drosophila is primarily involved in adult nervous system function and integrity. Cell 102, 437-449.

Parker, G.S., Eckert, D.M., and Bass, B.L. (2006). RDE-4 preferentially binds long dsRNA and its dimerization is necessary for cleavage of dsRNA to siRNA. RNA 12, 807-818.

Parker, G.S., Maity, T.S., and Bass, B.L. (2008). dsRNA Binding Properties of RDE-4 and TRBP Reflect Their Distinct Roles in RNAi. Journal of Molecular Biology 384, 967-979. 
Parrish, S., and Fire, A. (2001). Distinct roles for RDE-1 and RDE-4 during RNA interference in Caenorhabditis elegans. RNA 7, 1397-1402.

Pasquinelli, A.E., Reinhart, B.J., Slack, F., Martindale, M.Q., Kuroda, M.I., Maller, B., Hayward, D.C., Ball, E.E., Degnan, B., Muller, P., et al. (2000). Conservation of the sequence and temporal expression of let-7 heterochronic regulatory RNA. Nature 408, 86-89.

Pavelec, D.M., Lachowiec, J., Duchaine, T.F., Smith, H.E., and Kennedy, S. (2009). Requirement for the ERI/DICER Complex in Endogenous RNA Interference and Sperm Development in Caenorhabditis elegans. Genetics 183, 1283-1295.

Racen, E.L., McEwen, T.J., and Bennett, K.L. (2008). The intriguing interaction of Dicer (DCR1) with GLH-1, a P granule component in Caenorhabditis elegans. Developmental Biology 319 , 547-547.

Reinhart, B.J., Slack, F.J., Basson, M., Pasquinelli, A.E., Bettinger, J.C., Rougvie, A.E., Horvitz, H.R., and Ruvkun, G. (2000). The 21-nucleotide let-7 RNA regulates developmental timing in Caenorhabditis elegans. Nature 403, 901-906.

Ruby, J.G., Jan, C., Player, C., Axtell, M.J., Lee, W., Nusbaum, C., Ge, H., and Bartel, D.P. (2006). Large-scale sequencing reveals $21 \mathrm{U}-\mathrm{RNAs}$ and additional microRNAs and endogenous siRNAs in C. elegans. Cell 127, 1193-1207.

Ruby, J.G., Jan, C.H., and Bartel, D.P. (2007). Intronic microRNA precursors that bypass Drosha processing. Nature 448, 83-86.

Rybak-Wolf, A., Jens, M., Murakawa, Y., Herzog, M., Landthaler, M., and Rajewsky, N. (2014). A Variety of Dicer Substrates in Human and C-elegans. Cell 159, 1153-1167.

Sarkies, P., Ashe, A., Le Pen, J., McKie, M.A., and Miska, E.A. (2013). Competition between virus-derived and endogenous small RNAs regulates gene expression in Caenorhabditis elegans. Genome Research 23, 1258-1270.

Sawh, A.N., and Duchaine, T.F. (2013). A Truncated Form of Dicer Tilts the Balance of RNA Interference Pathways. Cell Reports 4, 454-463.

Schott, D.H., Cureton, D.K., Whelan, S.P., and Hunter, C.P. (2005). An antiviral role for the RNA interference machinery in Caenorhabditis elegans. Proceedings of the National Academy of Sciences of the United States of America 102, 18420-18424.

Seth, M., Shirayama, M., Gu, W.F., Ishidate, T., Conte, D., and Mello, C.C. (2013). The C. elegans CSR-1 Argonaute Pathway Counteracts Epigenetic Silencing to Promote Germline Gene Expression. Developmental Cell 27, 656-663.

Shih, J.D., Fitzgerald, M.C., Sutherlin, M., and Hunter, C.P. (2009). The SID-1 double-stranded RNA transporter is not selective for dsRNA length. RNA 15, 384-390.

Shih, J.D., and Hunter, C.P. (2011). SID-1 is a dsRNA-selective dsRNA-gated channel. RNA 17, 1057-1065.

Shirayama, M., Stanney, W., Gu, W.F., Seth, M., and Mello, C.C. (2014). The Vasa Homolog RDE-12 Engages Target mRNA and Multiple Argonaute Proteins to Promote RNAi in C. elegans. Current Biology 24, 845-851.

Sijen, T., Fleenor, J., Simmer, F., Thijssen, K.L., Parrish, S., Timmons, L., Plasterk, R.H.A., and Fire, A. (2001). On the role of RNA amplification in dsRNA-triggered gene silencing. Cell 107, 465-476.

Sijen, T., Steiner, F.A., Thijssen, K.L., and Plasterk, R.H.A. (2007). Secondary siRNAs result from unprimed RNA synthesis and form a distinct class. Science 315, 244-247. 
Simmer, F., Tijsterman, M., Parrish, S., Koushika, S.P., Nonet, M.L., Fire, A., Ahringer, J., and Plasterk, R.H.A. (2002). Loss of the putative RNA-directed RNA polymerase RRF-3 makes C. elegans hypersensitive to RNAi. Current Biology 12, 1317-1319.

Smardon, A., Spoerke, J.M., Stacey, S.C., Klein, M.E., Mackin, N., and Maine, E.M. (2000). EGO-1 is related to RNA-directed RNA polymerase and functions in germ-line development and RNA interference in C-elegans. Current Biology 10, 169-178.

Stefani, G., Chen, X.W., Zhao, H.Y., and Slack, F.J. (2015). A novel mechanism of LIN-28 regulation of let-7 microRNA expression revealed by in vivo HITS-CLIP in C. elegans. RNA 21, 985-996.

Steiner, F.A., Hoogstrate, S.W., Okihara, K.L., Thijssen, K.L., Ketting, R.F., Plasterk, R.H.A., and Sijen, T. (2007). Structural features of small RNA precursors determine Argonaute loading in Caenorhabditis elegans. Nature Structural \& Molecular Biology 14, 927-933.

Steiner, F.A., Okihara, K.L., Hoogstrate, S.W., Sijen, T., and Ketting, R.F. (2009). RDE-1 slicer activity is required only for passenger-strand cleavage during RNAi in Caenorhabditis elegans. Nature Structural \& Molecular Biology 16, 207-211.

Tabara, H., Grishok, A., and Mello, C.C. (1998). RNAi in C. elegans: soaking in the genome sequence. Science 282, 430-431.

Tabara, H., Sarkissian, M., Kelly, W.G., Fleenor, J., Grishok, A., Timmons, L., Fire, A., and Mello, C.C. (1999). The rde-1 gene, RNA interference, and transposon silencing in C-elegans. Cell 99, 123-132.

Tabara, H., Yigit, E., Siomi, H., and Mello, C.C. (2002). The dsRNA binding protein RDE-4 interacts with RDE-1, DCR-1, and a DExX-box helicase to direct RNAi in C-elegans. Cell 109, 861-871.

Thivierge, C., Makil, N., Flamand, M., Vasale, J.J., Mello, C.C., Wohlschlegel, J., Conte, D., and Duchaine, T.F. (2012). Tudor domain ERI-5 tethers an RNA-dependent RNA polymerase to DCR1 to potentiate endo-RNAi. Nature Structural \& Molecular Biology 19, 90-U114.

Tijsterman, M., Ketting, R.F., Okihara, K.L., Sijen, T., and Plasterk, R.H.A. (2002a). RNA helicase MUT-14-dependent gene silencing triggered in C-elegans by short antisense RNAs. Science 295, 694-697.

Tijsterman, M., Okihara, K.L., Thijssen, K., and Plasterk, R.H.A. (2002b). PPW-1, a PAZ/PIWI protein required for efficient germline RNAi, is defective in a natural isolate of C-elegans. Current Biology 12, 1535-1540.

Tonkin, L.A., and Bass, B.L. (2003). Mutations in RNAi rescue aberrant chemotaxis of ADAR mutants. Science 302, 1725.

Tonkin, L.A., Saccomanno, L., Morse, D.P., Brodigan, T., Krause, M., and Bass, B.L. (2002). RNA editing by ADARs is important for normal behavior in Caenorhabditis elegans. EMBO J 21, 6025-6035.

Tops, B.B.J., Plasterk, R.H.A., and Ketting, R.F. (2006). The Caenorhabditis elegans argonautes ALG-1 and ALG-2: Almost identical yet different. Cold Spring Harbor Symposia on Quantitative Biology 71, 189-194.

Tsai, H.Y., Chen, C.C.G., Conte, D., Moresco, J.J., Chaves, D.A., Mitani, S., Yates, J.R., Tsai, M.D., and Mello, C.C. (2015). A Ribonuclease Coordinates siRNA Amplification and mRNA Cleavage during RNAi. Cell 160, 407-419.

Tu, S.K., Wu, M.Z., Wang, J., Cutter, A.D., Weng, Z.P., and Claycomb, J.M. (2015). Comparative functional characterization of the CSR-1 22G-RNA pathway in Caenorhabditis nematodes. Nucleic Acids Research 43, 208-224. 
Vadla, B., Kemper, K., Alaimo, J., Heine, C., and Moss, E.G. (2012). lin-28 Controls the Succession of Cell Fate Choices via Two Distinct Activities. Plos Genetics 8, e1002588-e1002588.

Van Wynsberghe, P.M., Kai, Z.S., Massirer, K.B., Burton, V.H., Yeo, G.W., and Pasquinelli, A.E. (2011). LIN-28 co-transcriptionally binds primary let-7 to regulate miRNA maturation in Caenorhabditis elegans. Nature Structural \& Molecular Biology 18, 302-U386.

Vasale, J.J., Gu, W.F., Thivierge, C., Batista, P.J., Claycomb, J.M., Youngman, E.M., Duchaine, T.F., Mello, C.C., and Conte, D. (2010). Sequential rounds of RNA-dependent RNA transcription drive endogenous small-RNA biogenesis in the ERGO-1/Argonaute pathway. Proceedings of the National Academy of Sciences of the United States of America 107, 3582-3587.

Vasquez-Rifo, A., Bosse, G.D., Rondeau, E.L., Jannot, G., Dallaire, A., and Simard, M.J. (2013). A New Role for the GARP Complex in MicroRNA-Mediated Gene Regulation. Plos Genetics 9, e1003961-e1003961.

Vasquez-Rifo, A., Jannot, G., Armisen, J., Labouesse, M., Irfan, S., Bukhari, A., Rondeau, E.L., Miska, E.A., and Simard, M.J. (2012). Developmental Characterization of the MicroRNA-Specific C. elegans Argonautes alg-1 and alg-2. Plos One 7, e33750-e33750.

Wang, G., and Reinke, V. (2008). A C. elegans Piwi, PRG-1, regulates 21U-RNAs during spermatogenesis. Current Biology 18, 861-867.

Warf, M.B., Johnson, W.E., and Bass, B.L. (2011). Improved annotation of C. elegans microRNAs by deep sequencing reveals structures associated with processing by Drosha and Dicer. RNA 17, 563-577.

Warf, M.B., Shepherd, B.A., Johnson, W.E., and Bass, B.L. (2012). Effects of ADARs on small RNA processing pathways in C. elegans. Genome Research 22, 1488-1498.

Wedeles, C.J., Wu, M.Z., and Claycomb, J.M. (2013a). A multitasking Argonaute: exploring the many facets of C-elegans CSR-1. Chromosome Research 21, 573-586.

Wedeles, C.J., Wu, M.Z., and Claycomb, J.M. (2013b). Protection of Germline Gene Expression by the C. elegans Argonaute CSR-1. Developmental Cell 27, 664-671.

Welker, N.C., Habig, J.W., and Bass, B.L. (2007). Genes misregulated in C. elegans deficient in Dicer, RDE-4, or RDE-1 are enriched for innate immunity genes. RNA 13, 1090-1102.

Welker, N.C., Maity, T.S., Ye, X.C., Aruscavage, P.J., Krauchuk, A.A., Liu, Q.H., and Bass, B.L. (2011). Dicer's Helicase Domain Discriminates dsRNA Termini to Promote an Altered Reaction Mode. Molecular Cell 41, 589-599.

Welker, N.C., Pavelec, D.M., Nix, D.A., Duchaine, T.F., Kennedy, S., and Bass, B.L. (2010). Dicer's helicase domain is required for accumulation of some, but not all, C-elegans endogenous siRNAs. RNA 16, 893-903.

Whipple, J.M., Youssef, O.A., Aruscavage, P.J., Nix, D.A., Hong, C.J., Johnson, W.E., and Bass, B.L. (2015). Genome-wide profiling of the C. elegans dsRNAome. RNA 21, 786-800.

Wilkins, C., Dishongh, R., Moore, S.C., Whitt, M.A., Chow, M., and Machaca, K. (2005). RNA interference is an antiviral defence mechanism in Caenorhabditis elegans. Nature 436, 1044-1047.

Winston, W.M., Molodowitch, C., and Hunter, C.P. (2002). Systemic RNAi in C-elegans requires the putative transmembrane protein SID-1. Science 295, 2456-2459.

Winston, W.M., Sutherlin, M., Wright, A.J., Feinberg, E.H., and Hunter, C.P. (2007). Caenorhabditis elegans SID-2 is required for environmental RNA interference. Proceedings of the National Academy of Sciences of the United States of America 104, 10565-10570. 
Wu, D., Lamm, A.T., and Fire, A.Z. (2011). Competition between ADAR and RNAi pathways for an extensive class of RNA targets. Nature Structural \& Molecular Biology 18, 1094-U1024.

Xu, J., Mon, H., Kusakabe, T., Li, Z.Q., Zhu, L., Iiyama, K., Masuda, A., Mitsudome, T., and Lee, J.M. (2013a). Establishment of a soaking RNA interference and Bombyx mori nucleopolyhedrovirus (BmNPV)-hypersensitive cell line using Bme21 cell. Applied Microbiology and Biotechnology 97, 10435-10444.

Xu, J., Nagata, Y., Mon, H., Li, Z.Q., Zhu, L., Iiyama, K., Kusakabe, T., and Lee, J.M. (2013b). Soaking RNAi-mediated modification of Sf9 cells for baculovirus expression system by ectopic expression of Caenorhabditis elegans SID-1. Applied Microbiology and Biotechnology 97, 5921-5931.

Yang, Y.Z., Jittayasothorn, Y., Chronis, D., Wang, X.H., Cousins, P., and Zhong, G.Y. (2013). Molecular Characteristics and Efficacy of 16D10 siRNAs in Inhibiting Root-Knot Nematode Infection in Transgenic Grape Hairy Roots. Plos One 8, e69463-e69463.

Yigit, E., Batista, P.J., Bei, Y.X., Pang, K.M., Chen, C.C.G., Tolia, N.H., Joshua-Tor, L., Mitani, S., Simard, M.J., and Mello, C.C. (2006). Analysis of the C-elegans argonaute family reveals that distinct argonautes act sequentially during RNAi. Cell 127, 747-757.

Zhang, C., Montgomery, T.A., Fischer, S.E.J., Garcia, S., Riedel, C.G., Fahlgren, N., Sullivan, C.M., Carrington, J.C., and Ruvkun, G. (2012). The Caenorhabditis elegans RDE-10/RDE-11 Complex Regulates RNAi by Promoting Secondary siRNA Amplification. Current Biology 22, 881-890.

Zhang, C., Montgomery, T.A., Gabel, H.W., Fischer, S.E.J., Phillips, C.M., Fahlgren, N., Sullivan, C.M., Carrington, J.C., and Ruvkun, G. (2011). mut-16 and other mutator class genes modulate $22 \mathrm{G}$ and $26 \mathrm{G}$ siRNA pathways in Caenorhabditis elegans. Proceedings of the National Academy of Sciences of the United States of America 108, 1201-1208.

Zhang, L., Ding, L., Cheung, T.H., Dong, M.Q., Chen, J., Sewell, A.K., Liu, X., Yates, J.R., and Han, M. (2007). Systematic identification of C. elegans miRISC proteins, miRNAs, and mRNA targets by their interactions with GW182 proteins AIN-1 and AIN-2. Molecular Cell 28, 598-613.

Zhang, P.P., and Zhang, H. (2013). Autophagy modulates miRNA-mediated gene silencing and selectively degrades AIN-1/GW182 in C-elegans. EMBO Rep 14, 568-576.

Zhuang, J.J., and Hunter, C.P. (2012). The Influence of Competition Among C. elegans Small RNA Pathways on Development. Genes 3, 671-685.

Zinovyeva, A.Y., Bouasker, S., Simard, M.J., Hammell, C.M., and Ambros, V. (2014). Mutations in Conserved Residues of the C. elegans microRNA Argonaute ALG-1 Identify Separable Functions in ALG-1 miRISC Loading and Target Repression. Plos Genetics 10, e1004286-e1004286.

Zisoulis, D.G., Lovci, M.T., Wilbert, M.L., Hutt, K.R., Liang, T.Y., Pasquinelli, A.E., and Yeo, G.W. (2010). Comprehensive discovery of endogenous Argonaute binding sites in Caenorhabditis elegans. Nature Structural \& Molecular Biology 17, 173-U176. 